\title{
Validation of a German and English Version of the Revised Art-of-Living Inventory
}

\author{
Bernhard Schmitz@, Bettina Schumacher, Mira Schwarz, and Franziska Feldmann \\ Department of Psychology, Technical University of Darmstadt (TU Darmstadt), Germany
}

\begin{abstract}
It is an important goal for many people to achieve happiness or well-being. Research has shown the effects of various stand-alone strategies to increase well-being. However, it is unclear whether multiple strategies can enhance happiness. Art-of-living is defined as a combination of the most important strategies that lead to well-being. Based on philosophical theory and empirical studies, 11 strategy components have been identified. A basic questionnaire, the Art-of-Living Inventory (AOLI), which aims to measure these strategies, was validated in a German-speaking sample $(n=1,302)$ and an English-speaking sample $(n=2,166)$. Results confirmed the hypothesized factor structure which comprised 11 dimensions and at least weak measurement invariance. Further analyses demonstrated good internal consistency, retest reliability and convergent, and discriminant validity with respect to different indicators of well-being and the validation measures. Multiple regressions indicated that a combination of multiple components was significantly better at predicting well-being than even the best single component. Moreover, when compared to personality, art-of-living was demonstrated to have additional and distinct effects on well-being. In sum, the AOLI has promising measurement characteristics and may be applied in research studies to better understand well-being and in intervention studies aimed at enhancing well-being.
\end{abstract}

Keywords: well-being, art-of-living, happiness, validation

\section{The Importance of Happiness}

Since ancient times, people have wanted to lead a good life and be happy. Some philosophers suggest aiming for eudaimonic well-being, for instance, by realizing one's talents. Others believe that having fun by using the opportunities afforded by a hedonic life leads to well-being. Over the last few decades, researchers in positive psychology have developed a range of interventions for enhancing happiness (Sin \& Lyubomirsky, 2009). However, most of these interventions are conceptualized as stand-alone strategies. A holistic, integrated perspective that combines the main ways in which to achieve happiness is arguably missing from this literature. Our aim is to present an integrated approach that summarizes important pathways to well-being and to validate two versions of an instrument, one in a German-speaking and one in an English-speaking sample.

Art-of-living is described by Schmitz (2016), who also developed a German measurement instrument based on 17 dimensions, with a total of 131 items. However, due to its length, the instrument is impractical for use in evaluation studies. Our aim is therefore to develop a new, more parsimonious version of the art-of-living instrument, and to validate two versions, in a German and an English-speaking sample. We recommend using the revised version in future studies.

\section{The Importance of Well-Being}

Happiness is an important goal for many people. In psychological terms, happiness is most commonly defined as wellbeing (Diener et al., 1985). Well-being is an important and worthwhile goal that has positive effects across multiple life-domains such as marriage, friendship, work, and health (Lyubomirsky et al., 2005).

\section{Difference Between the Path and the Goal}

It is important to note Veenhoven's (2003) fundamental distinction between the pathways to achieving a good life (i.e., life chances) and the outcome, namely happiness (i.e., life results). This distinction plays a crucial role in the concept of art-of-living, and its relationship with wellbeing. As Veenhoven (2003) points out, some constructs of well-being do not sufficiently differentiate between the paths to happiness and the result of these strategies, namely, happiness or well-being. One example is the concept of psychological well-being (PWB), as suggested by Ryff (1989). Consider the PWB subfacet of relationships: to have good social relationships one can try to intensify contact with friends. This conflates the end with the means. 
Similarly, Huta and Waterman (2014) emphasize the use of adequate and precise terminology in describing the pathways leading to happiness (hedonia and eudaimonia).

\section{The Need for the Construct of Art-of-Living}

\section{Single Strategies or a Combination of Strategies}

The discipline of positive psychology has generated a substantial number of positive psychological interventions (PPIs), including the "gratitude letter," "positive writing," and "acts of kindness." Meta-analyses have demonstrated the effectiveness of these interventions for enhancing well-being (Bolier et al., 2013; Sin \& Lyubomirsky, 2009). However, many of these strategies are employed as stand-alone interventions. This raises the question as to whether combinations of individual strategies could further enhance the effectiveness of these types of interventions. In other words, does the integration of these strategies lead to more well-being? Interestingly, a meta-analysis by Hendriks et al. (2019) suggests that combined strategies do not necessarily lead to more well-being than stand-alone strategies. However, we argue that art-of-living represents a specific set of strategies that are most effective when they are combined.

\section{Does Art-of-Living Improve the Prediction of Well- Being Over and Above the Effect of Personality?}

One key theoretical difference between personality and artof-living is that personality is considered a stable trait, whereas art-of-living is conceptualized as a set of impermanent strategies, behaviors, or attitudes. It is therefore an empirical question as to whether art-of-living has incremental value in predicting well-being in addition to personality. We aim to answer this question by examining the incremental validity of the new art-of-living instrument with respect to well-being.

\section{Structural Definition of Art-of-Living}

In the following section, we will provide a structural definition of the concept of art-of-living and outline the main underlying assumptions.

(1) Art-of-living is defined as "all paths leading to wellbeing." In that sense, well-being is the construct to be predicted, while the pathways (art-of-living) are its predictors. Well-being has been defined and conceptualized in multiple ways. We refer to the well-being construct as described by Diener et al. (1985). It includes three dimensions of subjective well-being (SWB): positive affect, negative affect, and life satisfaction.
However, we intend to pursue a broader, more integrated concept of well-being, which empirically could be represented by constructs like "authentic happiness," "subjective happiness," and "flourishing."

(2) Given the observation that many PPIs have been assessed as stand-alone interventions, here we consider the effect of a combination of strategies and hypothesize that such a combination would more accurately predict well-being than any one individual strategy.

(3) We hypothesize that art-of-living is a superior predictor of well-being compared to personality.

(4) The strategies contained within art-of-living should show synergistic effects.

It follows then that art-of-living is a concept that can be defined and assessed empirically. In particular, it is possible to test whether a group of variables (the combination of strategies that define art-of-living) better predict well-being than stand-alone strategies.

\section{Theoretical Foundation: The Philosophical Art-of-Living (German: Lebenskunst) Theory by W. Schmid}

Having established its structural definition, we now elaborate on the concept of art-of-living at the content level, that is, to identify the factors that constitute art-of-living. Since art-of-living has been a topic of interest in philosophy for centuries, the theoretical foundations of our concept of art-of-living are grounded in philosophical considerations. More specifically, we build upon the work of Wilhelm Schmid $(1998,2004)$ who summarized the literature on art-of-living from the ancient Greeks and Epicureans to Hadot and Foucault. In this, Schmid focuses on self-care and not easy living, stating that "Art-of-living is not meant as the easy, happy-go-lucky life but conscious, reflected conduct of life" (Schmid, 2004, p. 9). The use of the term "art" reflects a view of art-of-living as a competency, and as a drive for achieving excellence. According to Schmid's conceptualization, the key attributes of art-of-living are living a conscious, effortful, self-determined, competent, reflective way of life. Furthermore, he relates art-of-living to the following aspects of the human being: the self, the body, the soul, and the mind.

\section{Introduction to Our Model of Art-of-Living}

Our model identifies five categories of strategies, namely those relating to the self, the body, the mind, the soul, and the context. With the exception of the latter, these categories reflect the attributes elaborated by Schmid (2004). 
Table 1. Overview of Art-of-Living subconstructs

\begin{tabular}{lll}
\hline Categories & Subconstruct & Example item \\
\hline Basic/Self & Self-determined way of living & | take responsibility for my own life. \\
& Self-knowledge & | make an effort to identify my personal strengths. \\
Body related & Savoring & | fully enjoy what life has to offer. \\
& Bodily care & | take care of my body. \\
Cognitive & Positive attitude toward life & Even in uncertain times, I usually expect the best. \\
& Reflection & I am often confused about the way I really feel. (reverse coded) \\
Motivational/Emotional & Optimization & I make clear to myself what my purpose in life is. \\
& Serenity & I consistently pursue the goals I set for my life. \\
Dealing with context & Coping & | stay calm even in difficult situations. \\
& Social contact & To solve a problem, I look at it from different angles. \\
& & I make an effort to stay in touch with my friends and acquaintances.
\end{tabular}

We describe these in more detail below and make reference to established psychological concepts where this is required. Table 1 provides an overview of the subconstructs of art-ofliving.

\section{Self-Care as the Basic Component of Art-of-Living}

According to Schmid (2004), self-care is a key aspect of artof-living. Self-care is related to the psychological concept of an authentic self-determined way of living. Central to this concept is the issue of taking responsibility for one's life. That is, each individual needs to take care of herself/himself. The sub-components of self-care are a self-determined way of living and self-knowledge.

\section{Self-Determined Way of Living}

The fulfillment of an authentic self-determined way of living provides a source of generalized satisfaction. Selfdetermination entails becoming the creator of one's own fate, setting a course of action, and experiencing agency in initiating and regulating one's own actions (Deci et al., 1989).

\section{Self-Knowledge}

To live a self-determined life, one must know oneself and one's own strengths and weaknesses. This component is labeled as self-knowledge (Vazire \& Carlson, 2010). It is the accurate self-perception about how one typically thinks, feels, and behaves.

\section{Body-Related Art-of-Living Strategies}

This category includes the strategies of savoring and taking care of the body.

\section{Savoring}

Savoring is engaging in things one likes and then savoring them, for instance, eating a fine meal and enjoying every bite. According to Bryant and Veroff (2006), savoring conveys the metaphorical search for delectable, delicious delights of the moment. Although the term is related to sensory experiences such as taste, it is not restricted to sensation but includes cognitive aspects such as imaging the next wonderful holiday.

\section{Bodily Care}

Surprisingly, the concept of flourishing (Seligman, 2011) does not involve the body, although it is clearly a key source of happiness (and pain). Art-of-living includes bodily care, recognizing that good bodily constitution is considered a prerequisite for well-being. Strategies that form part of bodily care include good nutrition and exercise (Wilkinson \& Whitehead, 2009).

\section{Cognitive Art-of-Living Strategies}

This category contains strategies relating to the mind, and includes positive attitudes toward life, reflection, and meaning in life.

\section{Positive Attitude Toward Life}

This concept is similar to optimism but differs to some extent because optimism is related to future events, whereas attitudes could be related to the past, the present, or the future.

\section{Reflection}

Self-reflection involves thinking about oneself, analyzing events, interpreting them, and deriving consequences (Malthouse \& Roffey-Barentsen, 2013). For instance, a scientist might reflect on his latest oral presentation which was criticized, and subsequently, conclude that more preparation would have yielded better results.

\section{Meaning}

Meaning in life is particularly important for achieving happiness. "Meaning in life is having three facets: one's life having value and significance, having a broader purpose in life, and one's life being coherent and making sense..." (Martelaa \& Steger, 2016, p. 531). 


\section{Motivational/Emotional Art-of-Living Strategies}

In addition to the aforementioned strategies related to the self, the body, and the mind, Schmid (2004) refers to the soul, a term that is not used in modern psychology. Instead, we opt to introduce motivational/emotional strategies.

\section{Motivational Strategy: Optimization}

Optimization is a particular motivational strategy that involves goal setting and then pursuing those goals, both of which are considered very important and effective methods for achieving well-being (Locke \& Latham, 2002). In this context, goal pursuing is labeled as optimization, meaning an attempt to reach goals, obtaining good results, and finding self-improvement.

\section{Emotional Strategy: Serenity}

Identifying a single emotional strategy from the available set is not a trivial task. We opt for serenity or keeping calm even in difficult situations, a skill that ancient philosophers acknowledged as a powerful way to maintain a good state of mind. More recently, Kreitzer et al. (2009) demonstrated that serenity is positively related to positive affect.

\section{Managing Context as an Art-of-Living Strategy}

Context is only implicitly addressed in Schmid's (2004) system, although he emphasizes the importance of dealing with events and other people.

\section{Coping With Events}

People cannot fully determine their own lives because they are also influenced by external events. It is important to note that the effect of any kind of event can be mitigated by the actions of the individual, that is, their coping strategies. Art-of-living, therefore, includes coping as a way of handling these external events. Coping is defined as dealing with stressful demands that are considered to exceed the resources of the person (Lazarus \& Folkman, 1984).

\section{Social Contact}

Although the individual is at the center of the art-of-living concept, the individual should be approached as part of, and influenced by their environment. The social environment (family, friends, and other important people) is, therefore, a key component. Individuals can affect their social environment, for instance, by giving social support or by engaging in constructive interaction with those around them. Social activities, therefore, have an effect on the well-being of the individual.

\section{Comment on the Category Designations and Their Exhaustiveness}

The assignment of the strategies to distinct categories, such as mind or soul, is not unambiguous. Savoring, for instance, is assigned to the body because the senses play an important role. At the same time, savoring has cognitive aspects, such as when one imagines a wonderful future.

Another important consideration is that the list of strategies is by no means exhaustive. We simply offer a preliminary classification and encourage further empirical research to test if additional strategies meet the criterion of leading to well-being.

\section{Research Questions}

The aim of the study is to examine the measurement qualities and to validate a new instrument to measure the concept of art-of-living. The reason for developing this revised instrument is two-fold. First, the revision offers a more parsimonious and a conceptually more stringent version of the original art-of-living instrument. Second, the new instrument offers a German and an English version. For further details about the revision process, see the supplementary material 1 (Schmitz et al., 2021).

Our study aimed to address the following research questions:

Research Question 1 (RQ1): Does the factor structure correspond to the 11 theoretical dimensions? Are the factor structures for the two languages similar (measurement invariance)?

Research Question 2 (RQ2): Do the questionnaire scales show sufficient reliability (internal consistency, retest reliability)?

Research Question 3 (RQ3): Is the instrument valid? To this end, we examine multiple aspects of validity,

(a) Convergent validity: Does art-of-living correlate with well-being?

(b) Convergent and divergent validity: Does art-of-living correlate with similar constructs (Resilience, Mindfulness), and can it be distinguished from unrelated constructs (Egoism, Perfectionism)?

(c) Does art-of-living correlate with other more objective criteria, such as the Situational Judgement Test (SJT) for emotional intelligence?

(d) To what extent do the components of art-of-living predict well-being?

(e) Do multiple components improve the prediction of well-being compared to a single component?

(f) Incremental validity (compared to the Big Five): Do art-of-living components improve the prediction of well-being over and above the effect of personality?

Research Question 4 (RQ4): Are there synergistic effects between art-of-living subconstructs? That is, 
how does common variance compare to unique components of variance in predicting well-being?

\section{Method}

\section{Sample}

We conducted four studies with the German questionnaire and five with the English questionnaire. The validating instruments differed between studies to allow assessment of a more extensive set of criteria. For an overview of the instruments used in the studies, see the supplementary material 2 (Schmitz et al., 2021).

The German sample comprised 1,302 participants (927 women, $375 \mathrm{men})$. Their mean age was 31.0 years $(S D=$ 12.6). The English sample comprised 2,166 participants (1,572 women, 594 men). The mean age was 31.9 years $(S D=13.5)$.

The five English subsamples were E1 $(n=207)$, E2 $(n=$ 245), E3 $(n=207), \mathrm{E} 4(n=903)$, and E5 $(n=604)$. The four German subsamples were G1 $(n=407), \mathrm{G} 2(n=210)$, G3 $(n=293)$, and G4 $(n=392)$.

\section{Procedure}

To recruit participants for the online assessment, active (snowball technique) and passive (invitation text with a link to our website) advertisement methods in local magazines and on the Internet were combined to reach a broad public. For the English sample, colleagues from foreign universities were asked to provide support. Participants gave informed consent. Anonymity was ensured. The subset of participants who were asked to take part in a retest of art-of-living instrument generated individual codes so that their responses could be matched.

\section{Translation}

The German version of the questionnaire was translated into English following the guidelines of the European social survey program, which recommends parallel translation (Harkness, 2007). Different experts translated the questionnaire independently and the results were subsequently compared. Next, a back-translation was conducted by a bilingual native English speaker with experience in scientific psychology. The next step was adjudication, that is, further examination by an independent expert. Finally, a group of six experts compared the back-translated version and the original version, and any discrepancies were discussed to optimize item formulations.

\section{Instruments}

\section{The Art-of-Living Inventory (AOLI)}

The AOLI consists of 11 subscales and a total of 35 items. This instrument is a conceptual and empirical revision of a validated German questionnaire consisting of 131 items (Schmitz, 2016). The revision was based on a series of studies using exploratory factor analyses and correlations with measures of well-being. The subscales (cf. Table 1) are a self-determined way of living, self-knowledge, savoring, caring for the body, a positive attitude toward life, reflection, meaning, serenity, optimization, coping, and social contact. The items are measured with a 6-point Likert scale $(1=$ strongly disagree, 6 = strongly agree $)$. Cronbach's $\alpha$ for the overall scale was .92 both for the German-speaking sample and the English-speaking sample. Cronbach's $\alpha$ for the subscales are presented in Table 2. All values for $\alpha$ were considered "good" $(\geq .80)$ for both samples. However, it should be noted that the subscales contain only 3-4 items.

\section{Instruments: English and German Samples}

Detailed information is only provided for the main instruments. We indicate whether the instruments were used in the English, the German version, or in both. For the other validation instruments, and more information, see the supplementary material 3 (Schmitz et al., 2021). The $\alpha$ s presented here stem from analyses of our data.

\section{Authentic Happiness Inventory (AHI)}

The AHI is an indicator of well-being developed by Seligman et al. (2005). It consists of 24 items. For the German sample, the version of Proyer et al. (2017) was used. In our study Cronbach's $\alpha$ was .93/.92 (English/German).

\section{Subjective Happiness Scale (SHS)}

The SHS is an additional indicator of subjective wellbeing (Lyubomirsky \& Lepper, 1999). It is defined as an individual's assessment of whether they feel happy or not. The German version was validated by Swami et al. (2009). In our study Cronbach's $\alpha$ was .84/.85 (English/German).

\section{Satisfaction with Life Scale (SWLS)}

The SWLS measures subjective well-being as global life satisfaction (Diener et al., 1985). It consists of five items rated from $1=$ strongly disagree to $7=$ strongly agree. For the German sample, the version developed by Glaesmer et al. (2011) was applied. In our study Cronbach's $\alpha$ was $.86 / .86$ (English/German).

\section{Flourishing Scale (FS)}

Flourishing is a concept of well-being in a broader sense, incorporating theories of psychological potential, human functionality, and social relationships. The FS as described 
Table 2. Means (M), Standard deviations (SD), retest, and Cronbach's $\alpha$

\begin{tabular}{|c|c|c|c|c|c|c|c|c|c|c|}
\hline \multirow[b]{2}{*}{ Subscale } & \multicolumn{3}{|c|}{ German $n=1,302$} & \multirow{2}{*}{$\frac{\text { Study G1 }}{r_{\mathrm{tt}}}$} & \multirow{2}{*}{$\frac{\text { Study G2 }}{r_{\mathrm{tt}}}$} & \multirow{2}{*}{$\frac{\text { Study } \mathrm{G} 4}{r_{\mathrm{tt}}}$} & \multicolumn{3}{|c|}{ English $n=2,166$} & \multirow{2}{*}{$\frac{\text { Study E3 }}{r_{\mathrm{tt}}}$} \\
\hline & M & $S D$ & $\alpha$ & & & & M & $S D$ & $\alpha$ & \\
\hline Self-determined way of living & 4.87 & 0.86 & .81 & .67 & .76 & .82 & 4.82 & 0.83 & .82 & .61 \\
\hline Self-knowledge & 4.22 & 0.93 & .80 & .64 & .67 & .80 & 4.56 & 0.89 & .82 & .70 \\
\hline Savoring & 4.63 & 0.92 & .81 & .68 & .76 & .73 & 4.81 & 0.81 & .82 & .81 \\
\hline Bodily care & 4.07 & 1.01 & .82 & .78 & .82 & .88 & 4.19 & 1.06 & .84 & .82 \\
\hline Positive attitude toward life & 4.23 & 1.02 & .80 & .78 & .77 & .85 & 4.48 & 0.98 & .82 & .80 \\
\hline Reflection & 3.50 & 1.24 & .85 & .74 & .71 & .82 & 3.76 & 1.19 & .87 & .88 \\
\hline Meaning & 4.36 & 1.01 & .80 & .71 & .82 & .83 & 4.49 & 0.97 & .81 & .86 \\
\hline Optimization & 4.45 & 0.93 & .80 & .67 & .80 & .77 & 4.56 & 0.89 & .82 & .79 \\
\hline Serenity & 3.88 & 1.08 & .82 & .77 & .80 & .72 & 4.33 & 1.06 & .83 & .84 \\
\hline Coping & 4.47 & 0.87 & .81 & .66 & .67 & .65 & 4.77 & 0.76 & .82 & .74 \\
\hline Social contact & 4.94 & 0.80 & .82 & .67 & .73 & .64 & 5.12 & 0.69 & .83 & .76 \\
\hline Total art-of-living & 4.33 & 0.59 & .92 & .80 & .83 & .86 & 4.52 & 0.58 & .92 & .88 \\
\hline
\end{tabular}

Note. $r_{t+}=$ Retest reliability; G1 = German study 1, part of the sample, Retest, $n=175 ;$ G2 = German study 2, part of the sample, Retest, $n=155 ;$ G4 $=$ German study 4, part of the sample, Retest, $n=95$; E3 = English study 3, part of the sample, Retest, $n=93$. $p<.001$ for all correlations.

by Diener et al. (2010) and the German version (FS-D) (Esch et al., 2013) was applied. In our study Cronbach's $\alpha$ was .86/.88 (English/German).

\section{Data Analysis}

The R software was used for all analyses (R Core Team, 2015). The use of special R-packages will be explained for specific analyses. The data were checked for consistency, that is, double codes and unusual answer structures. For Confirmatory Factor Analysis (CFA) models and measurement invariance, we used the Lavaan package (Rosseel, 2012). The test of measurement invariance is very important (Greiff \& Scherer, 2018) because it guarantees the comparability of operations for the different groups. First, a multiple-group CFA was performed without equality constraints to test for configural invariance. A fit of this model would indicate that the factor structures were equal across the groups. Next, the weak invariance or metric invariance is tested by constraining the factor loadings to be equivalent across groups. The next step is to constrain intercepts across groups. If this model fits, scalar or strong invariance can be stated. In case this model also fits, the means will be constrained.

In terms of model fit criteria, we draw upon the Comparative Fit Index (CFI) that should be greater than .95 (Hu \& Bentler, 1999), and the Root Mean Square Error of Approximation (RMSEA) where values of less than .06 indicate a good fit (Hu \& Bentler, 1999). As simulation studies have demonstrated that the $\chi^{2}$ test for differences between nested models may lead to incorrect decisions, the recommendations made by Chen (2007) for model comparisons were applied. Non-invariance is accepted if $\triangle \mathrm{CFI}$ is $>.010$ and $\triangle$ RMSEA > .01.

\section{Results}

\section{Factor Structure}

The factor structure fit with the 11 theoretical dimensions was examined and whether the factor structures were similar in the two languages (measurement invariance).

To gain insight into the factor structure, first, an Exploratory Factor Analysis (EFA) was performed. Application of the scree criterion yielded two breaks: one pointing to a single factor solution and a second to an 11-factor model. The parallel analyses clearly pointed to 11 factors. The one factor explained $31.8 \%$ of the variance.

To test our assumptions about the factor structure, a CFA with 11 factors, as indicated by the theory was conducted. The factors were allowed to correlate. Supplementary material 4 (Schmitz et al., 2021) shows the loadings, which were all higher than .45 , and most were greater than .6. Supplementary material 5 (Schmitz et al., 2021) displays the factor correlations. The fit indices were $\chi^{2}(505)=1,183.42, \mathrm{CFI}=$ .976 and RMSEA $=.030$ for the German sample and, for the English sample, $\chi^{2}(505)=1,933.56$, CFI $=.966$ and RMSEA $=.031$. Although the $\chi^{2}$ values are statistically significant, the CFI values are both greater than .95 and the RMSEA values are both lower than .06, which shows a good fit.

The fit indices for measurement invariance for language yielded CFI $=.966$ and RMSEA $=.035$ for configural invariance (see supplementary material 6, Schmitz et al., 2021). Comparing different kinds of measurement invariance, this material shows that the BIC is minimal for the equality of loadings. The $\chi^{2}$ values for the model comparisons are all statistically significant $(p<.001)$ but the CFI values for all models are greater than .95 and the RMSEA is lower than .06, thereby showing an acceptable model fit $(\mathrm{Hu} \&$ 
Bentler, 1999). In addition, in accordance with Chen (2007), the observation that $\triangle C F I$ is lower than .01 and $\triangle$ RMSEA is lower .01 supports the invariance of means.

We also examined measurement invariance with respect to gender. The tests of measurement invariance for gender were computed separately for the English and German samples. The results are also provided in supplementary material 6 (Schmitz et al., 2021). A similar interpretation applies. Although the $\chi^{2}$ for the model comparisons are all statistically significant $(p<.05)$, the CFI for all models is greater than .95 and the RMSEA is lower than .06, showing an acceptable model fit (Hu \& Bentler, 1999). Here too, the $\triangle \mathrm{CFI}$ is lower than .010, and $\triangle \mathrm{RMSEA}$ is lower than .01, supporting the invariance of means with respect to gender.

Because the EFA also suggested a one-factor model and we also want to apply an overall score that represents the general art-of-living, a second-order factor model was tested in addition to the 11-factor model (Figure 1). If a second-order factor can be fitted, the use of an overall score is justified. The fit indices were $\chi^{2}(549)=3,567.4, \mathrm{CFI}=.951$ and RMSEA $=.040$. Again, the CFI value is greater than .95 and the RMSEA is lower than .06, which shows an acceptable fit, but a poorer fit compared to the first order 11-factor model. The loadings of the second-order factor are presented in Figure 1.

\section{Reliability}

It was tested whether the scales of the new instrument show sufficient reliability (internal consistency, retest reliability).

The supplementary material 7 Table (Schmitz et al., 2021) shows the means, standard deviations, and corrected part-whole correlations for the subscale items. For the German sample, the part-whole correlations were all higher than .5 and for the English sample, the part-whole correlations were of a similar magnitude.

Table 2 shows the values for Cronbach's $\alpha$ for the AOLI subscales (all $\geq .8$ ). The overall Cronbach's $\alpha$ was .92 for both the German sample and the English sample. The analyses for the retest reliability were performed for the subsamples only (see Table 2). Retest reliability coefficients for the AOLI total were $.80, .83, .86$, and .88 , which is considered good. For the subscales (which consist only of three or four items) all coefficients were greater than .61 and most were over .7.

\section{Validity}

The discussion of validity centers around six detailed questions (see Research Questions), the first three of which were answered using correlational analyses.

\section{Correlational Analyses}

Do Art-of-Living Strategies Correlate With Well-Being? German sample: Table 3 shows the associations between artof-living and various constructs capturing well-being, such as the SWLS, AHI, SHS, and the FS-D. Correlations between the SWLS and the AOLI total were $r=.49, r=$ .57 and $r=.64$. The AOLI total also correlated with the AHI $(r=.68)$, the SHS $(r=.62)$, and the FS-D $(r=.71)$. For correlations with the subscales, see supplementary material 8 Table (Schmitz et al., 2021).

English sample: Table 3 highlights strong associations between art-of-living and the various constructs capturing well-being. Strong correlations between the AOLI total and SWLS scores were found in three samples $(r=.68$, $r=.49, r=.60)$. The AOLI total also correlated with the AHI $(r=.71)$ and the two flourishing measures (PERMA: $r=.65$, FS: $r=.68$ ). Overall, the correlations between artof-living and different well-being measures were in the .50-70 range, all in the expected direction. For correlations with the subscales, see supplementary material 8 Table (Schmitz et al., 2021).

\section{Convergent and Divergent Validity}

German sample: As shown in Table 3, the AOLI total correlated with similar construct measures, that is, with mindfulness $(r=.66)$ and with resilience $(r=.66)$. The expected discriminant relationship with egoism was also supported $(r=-.30)$.

English sample: Table 3 shows the measures for convergent validity, for instance, the correlation between the AOLI total and life orientation $(r=.68)$, meaning $(r=$ $.64)$ and resilience $(r=.67)$, all showing the expected high positive values. With regards to divergent validity, the correlation with the construct of perfectionism is low $(r=$ $-.10)$, as expected.

Overall, the results of the validation analyses lead us to several important conclusions. Firstly, the relationship between art-of-living and well-being is strong, as expected, although there is some variability depending on the measures and the samples. Art-of-living, therefore, summarizes important ways in which to enhance well-being. Secondly, the relationships with similar constructs like mindfulness and resilience are in the expected direction according to the theory, while the relationship with divergent constructs such as perfectionism was negligible.

\section{Validation With More Objective Variables}

As more objective variables, we measured emotional intelligence with a SJT. The correlations with art-of-living are shown in Table 3. The correlations between the AOLI total and emotional intelligence with respect to others, and with respect to oneself were both statistically significant, $r=.47$, $p<.001$ and $r=.51, p<.001$, respectively. 


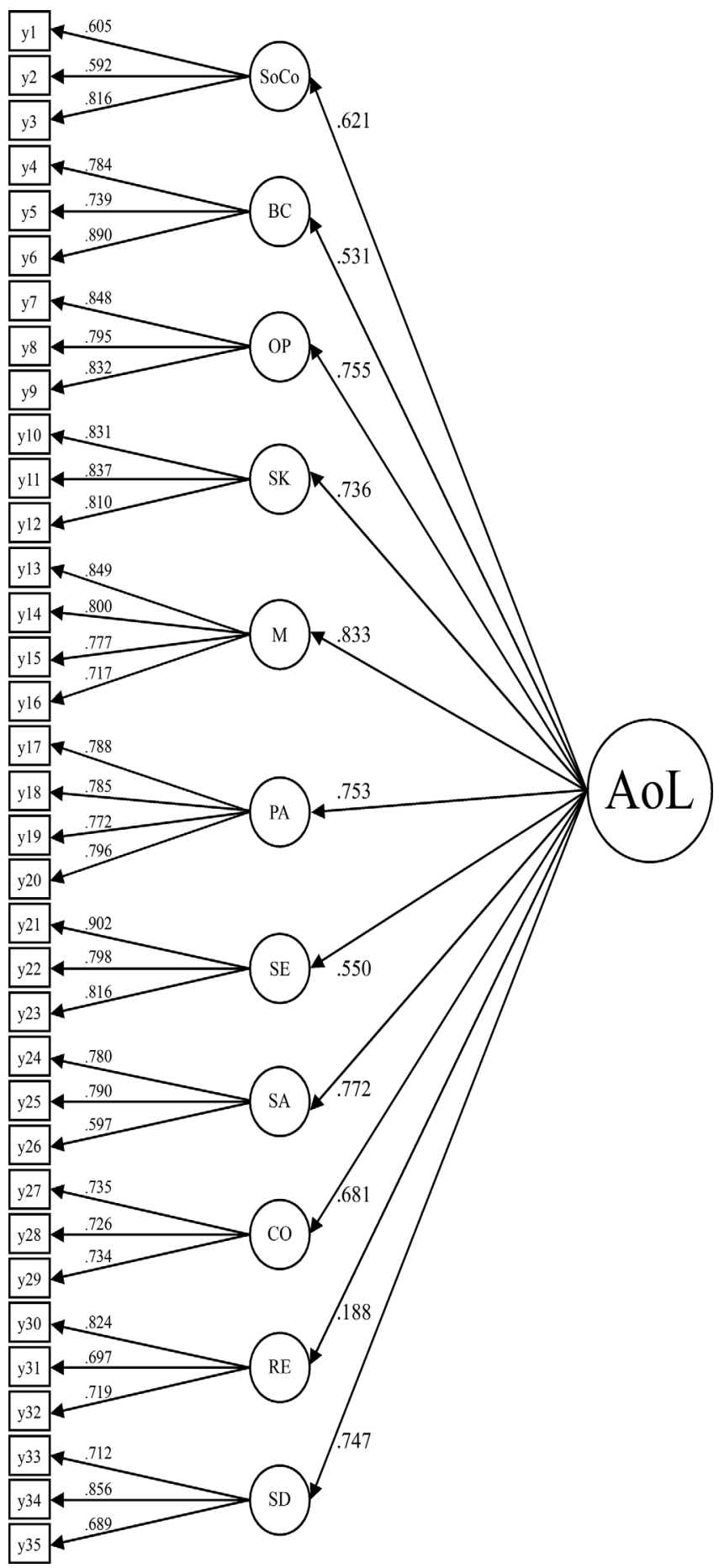

Figure 1. Model for the second-order factor analysis. SoCo = Social Contact; $B C=$ Bodily Care; OP = Optimization; SK = Self-knowledge; $\mathrm{M}=$ Meaning; PA = Positive Attitude Toward Life; SE = Serenity; SA = Savoring; CO = Coping; RE = Reflection; SD = Self-Determined Way of Living; AoL $=$ Art-of-Living.

\section{Multiple Regression Analyses}

\section{Can Well-Being be Predicted by the Components} of Art-of-Living?

Having demonstrated that art-of-living total correlates with different measures of well-being, the next step was to analyze the extent to which art-of-living predicts wellbeing.

The multiple regression shows (see Table 4), for the German sample, that $35 \%$ of the variance in SWLS can be explained by art-of-living. For the English sample, the 
Table 3. Correlations between art-of-living and well-being, convergent/divergent validation

\begin{tabular}{|c|c|c|c|}
\hline \multicolumn{2}{|l|}{ German } & \multicolumn{2}{|l|}{ English } \\
\hline Well-being & AoL & Well-being & AoL \\
\hline$\overline{\mathrm{AHI}}{ }^{6}$ & $.68^{* \star *}$ & $\mathrm{AHI}^{5}$ & $.71 * \star \star$ \\
\hline $\mathrm{SHS}^{7}$ & $.62 * \star \star$ & $\mathrm{SHS}^{1}$ & $.59 * * *$ \\
\hline SWLS ${ }^{6}$ & $.49 * * *$ & SWLS ${ }^{2}$ & $.68^{\star \star \star}$ \\
\hline SWLS ${ }^{7}$ & $.57 * \star \star$ & SWLS ${ }^{4}$ & $.49 * * *$ \\
\hline$S W L S^{8}$ & $.64^{\star \star \star}$ & SWLS ${ }^{5}$ & $.60 * \star *$ \\
\hline \multirow[t]{4}{*}{$F S-D^{8}$} & 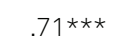 & Flourishing $(F S)^{5}$ & $.68^{\star \star \star}$ \\
\hline & & PERMA $^{4}$ & $.65^{\star \star *}$ \\
\hline & & Positive Affect ${ }^{1}$ & $.56^{\star * *}$ \\
\hline & & Negative Affect ${ }^{1}$ & $-.54 * \star \star$ \\
\hline Resilience $^{6}$ & $.66^{\star \star \star}$ & Resilience $^{4}$ & $.67 * \star \star$ \\
\hline Mindfulness ${ }^{6}$ & $.66^{\star \star \star}$ & Eudaimonic well-being ${ }^{5}$ & $.69 * * *$ \\
\hline Emotional intelligence Other ${ }^{7}$ & $.47 * \star \star$ & Who $5^{4}$ & $-.53^{* \star *}$ \\
\hline Emotional intelligence $\mathrm{Own}^{7}$ & $.51 * * \star$ & Psychological well-being ${ }^{3}$ & \\
\hline Egoism $^{8}$ & $-.30 * \star \star$ & Self-acceptance ${ }^{3}$ & $.66^{* * *}$ \\
\hline Neuroticism BFI-10 6 & 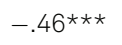 & Purpose $^{3}$ & $.35 * * *$ \\
\hline Extraversion $\mathrm{BFI}-10^{6}$ & $.28 * * *$ & Environmental mastery ${ }^{3}$ & $.64^{\star * *}$ \\
\hline Openness BFI-10 6 & $.11^{*}$ & Positive relations ${ }^{3}$ & $.50 * \star *$ \\
\hline Agreeableness BFI-10 $10^{6}$ & $.11 *$ & Personal growth ${ }^{3}$ & $.55^{\star \star \star}$ \\
\hline Conscientiesness BFI-10 6 & $.37 * \star \star$ & Autonomy ${ }^{3}$ & $.42^{\star \star \star}$ \\
\hline Neuroticism NEO-FF| ${ }^{8}$ & $-.72^{\star \star \star}$ & Life orientation $^{3}$ & $.68 * \star *$ \\
\hline Extraversion NEO-FFI ${ }^{8}$ & $.58 * \star \star$ & Sense of Coherence ${ }^{4}$ & $.57^{\star \star \star}$ \\
\hline Openness NEO-FFI ${ }^{8}$ & $.17 *$ & Meaning (MEMS) ${ }^{5}$ & $.64^{* \star *}$ \\
\hline Agreeableness NEO-FFI ${ }^{8}$ & $.21 * \star \star$ & Anxiety $(\mathrm{Gad}-7)^{5}$ & $-.49 * * *$ \\
\hline \multirow[t]{2}{*}{ Conscientiousness NEO-FFI ${ }^{8}$} & $.40 * \star \star$ & & \\
\hline & & Self-oriented perfectionism ${ }^{3}$ & -.10 \\
\hline
\end{tabular}

Note. AoL = Art-of-living; SWLS = Satisfaction with Life Scale; SHS = Subjective Happiness Scale; AHI = Authentic Happiness Inventory; FS-D = Flourishing Scale - German; BFI-10 = Big Five Inventory-10; NEO-FFI = NEO Five Factor Inventory. ${ }^{1}$ E1: English study 1, $n=207 .{ }^{2} \mathrm{E} 2:$ English study 2, $n=245$.

${ }^{3}$ E3: English study 3, $n=207 .{ }^{4}$ E4: English study 4, $n=903 .{ }^{5}$ E5: English study 5, $n=604 .{ }^{6}$ G1: German study 1, $n=407 .{ }^{7}$ G2: German study 2, $n=210$.

${ }^{8}$ G4: German study $4, n=392 .{ }^{*} p<.05 ;{ }^{*} p<.01 ; * * * p<.001$.

amount of variance in SWLS which can be explained by art-of-living is $41 \%$.

\section{Multicomponent vs. Single Component Prediction}

We performed multiple regression via the forward method with well-being indicators as criteria and art-of-living components as predictors. The results are shown in Table 4. In addition, the $R^{2}$ of the first predictor (single component) and the additional $R^{2}$ for the group containing the other of the 11 components were evaluated. In the English subsamples, the single component explained 32\% of the SWLS variance, and the other components explained a further $9 \%$. For the German subsamples, these values were $21 \%$ and $14 \%$, respectively, in both cases suggesting that the other components add statistically significantly to the prediction of well-being. The effect was even more pronounced for other wellbeing constructs, that is, the SHS and AHI.

We also performed multiple regression analyses with structural equation models (SEM) using the R-package Lavaan (Rosseel, 2012). The difference with the results shown in Table 4 is that the analyses using SEM were based on the items incorporating latent structures for the scales. The results were similar and do not add information.

\section{Can Art-of-Living Predict Well-Being Better Than Personality (Incremental Validity Compared} to the Big Five)?

With respect to incremental validity, we tested if art-ofliving can enhance the prediction of well-being compared to personality domains measured by the Big Five.

Table 4 summarizes the results. In the first step of testing the multiple regression model, well-being (SWLS) was predicted by the Big Five $\left(R^{2}=.10\right)$. After adding the subscales of the AOLI as predictors in the second step, the amount of variance explained is $33 \%$. The $\Delta R^{2}=.23, p<.001$, indicating that the prediction of well-being is substantively improved by the inclusion of art-of-living in addition to personality. Because the measure of the Big Five in our study contains only two items for each dimension it could be that the analyses of incremental validity are due to this measurement aspect. Because we could not apply more extensive measures of the Big Five in the whole sample, 
Table 4. Multiple regression for well-being

\begin{tabular}{|c|c|c|c|c|c|c|}
\hline Criterion & Sample & German/English & Sample size & $R^{2}$ & $\Delta R^{2}$ & Predictors \\
\hline \multicolumn{7}{|c|}{ Prediction of well-being by art-of-living } \\
\hline SWLS & $\mathrm{G} 1, \mathrm{G} 2, \mathrm{G} 4$ & G & 1,009 & .35 & & All components AoL \\
\hline SWLS & $\mathrm{E} 2, \mathrm{E} 4, \mathrm{E} 5$ & E & 1,752 & .41 & & All components AoL \\
\hline SHS & G2 & G & 210 & .51 & & All components AoL \\
\hline $\mathrm{AHI}$ & E5 & $\mathrm{E}$ & 604 & .57 & & All components AoL \\
\hline \multicolumn{7}{|c|}{ Multicomponent compared to single component art-of-living } \\
\hline SWLS & $\mathrm{G} 1, \mathrm{G} 2, \mathrm{G} 4$ & G & 1,009 & .21 & & Single component \\
\hline SWLS & $\mathrm{G} 1, \mathrm{G} 2, \mathrm{G} 4$ & G & 1,009 & .14 & & Other components \\
\hline SWLS & $\mathrm{E} 2, \mathrm{E} 4, \mathrm{E} 5$ & $E$ & 1,752 & .32 & & Single component \\
\hline SWLS & $\mathrm{E} 2, \mathrm{E} 4, \mathrm{E} 5$ & $E$ & 1,752 & .09 & & Other components \\
\hline SHS & G2 & G & 210 & .38 & & Single component \\
\hline SHS & G2 & G & 210 & .14 & & Other components \\
\hline $\mathrm{AHI}$ & E5 & E & 604 & .38 & & Single component \\
\hline $\mathrm{AHI}$ & E5 & E & 604 & .19 & & Other components \\
\hline \multicolumn{7}{|c|}{ Incremental validity compared to Big Five (BFI-10) } \\
\hline SWLS & G1, G2 & G & 617 & .10 & - & Big Five \\
\hline SWLS & G1, G2 & G & 617 & .33 & .23 & Big Five + All components AoL \\
\hline SHS & G2 & G & 210 & .33 & - & Big Five \\
\hline SHS & G2 & G & 210 & .55 & .22 & Big Five + All components AoL \\
\hline $\mathrm{AHI}$ & G1 & G & 400 & .29 & - & Big Five \\
\hline $\mathrm{AHI}$ & G1 & G & 400 & .55 & .26 & Big Five + All components AoL \\
\hline \multicolumn{7}{|c|}{ Incremental validity compared to Big Five (NEO-FFI) } \\
\hline SWLS & G4 & G & 400 & .44 & - & Big Five \\
\hline SWLS & G4 & G & 400 & .54 & .10 & Big Five + All components AoL \\
\hline FS-D & G4 & G & 400 & .58 & - & Big Five \\
\hline FS-D & G4 & G & 400 & .68 & .10 & Big Five + All components AoL \\
\hline
\end{tabular}

Note. G1, G2, G4 = German studies 1, 2, 4; $n=1$,009. E2, E4, E5 = English studies 2, 4, 5; $n=1,752$. G1, G2 = German studies 1, 2; $n=617$. G1 = German study $1 ; n=407 . \mathrm{G} 2=$ German study $2 ; n=210$. E5 = English study $5 ; n=604$. AoL = Art-of-living. Big Five upper table BFI-10; Big Five lower table NEO-FFI; SWLS = Satisfaction with Life Scale; SHS = Subjective Happiness Scale; AHI = Authentic Happiness Inventory; FS-D = Flourishing Scale_German. All $R^{2} p<$ $.001 ; \Delta R^{2} p<.001$.

the NEO Five-Factor Inventory (NEO-FFI) (Borkenau \& Ostendorf, 2008) was administered, which comprises 12 items for each dimension, in a subsample. The same analysis was performed to test the incremental validity in this subsample. SWLS and FS-D were used as outcome variables. The results (cf. Table 4) showed a statistically significant increase in the explained variance by including art-of-living.

Regarding synergistic effects of the art-of-living subcomponents the correlations of the subscales are contained in the supplementary material 9 (Schmitz et al., 2021). The proportion of common variance compared to the unique variance of the subcomponents turned out to be higher showing synergistic effects, see supplementary material 10 (Schmitz et al., 2021).

\section{Discussion}

The aim of our study was to investigate the psychometric quality of our new AOLI. Demonstrating the new instrument's sufficient psychometric qualities is a prerequisite for its application as a valuable research tool, especially in interventions aiming to enhance well-being.

Factor structure, reliability, different forms of validity, and synergistic relationships between the components were analyzed.

\section{Factor Structure}

We were able to confirm the 11-dimensional structure as suggested by the theory. Also, measurement invariance regarding the German and English samples was demonstrated, at least as weak metric invariance. If the criteria defined by Chen (2007) are accepted with respect to $\triangle \mathrm{CFI}$ and $\triangle$ RMSEA, then the invariance of the means could also be accepted. The same applies to invariance with respect to gender.

\section{Reliability}

The overall internal consistency was found to be excellent with a Cronbach's $\alpha$ of .92 for both the German and the 
English versions. The subscales all had good internal consistency (Cronbach's $\alpha \geq .80$ ), which is remarkable for subscales that mainly comprise three items. The retest coefficient for the overall scale was at least .80 in all studies. All this indicates that the questionnaire is acceptable with respect to reliability.

\section{Validity}

Because art-of-living is conceptualized as the pathway to well-being, there must be significant relationships with well-being constructs. We examined different samples and different indicators of well-being, such as subjective well-being, authentic happiness, subjective happiness, and flourishing, finding substantial correlations with the AOLI in the expected directions, for all the criteria.

Associations with similar constructs including resilience, mindfulness, optimism, coherence, and meaning were also assessed. The correlations were all in the expected direction. We were also able to show correlations with more objective criteria, namely, a situational judgment test for emotional intelligence. With respect to divergent validity, a clear distinction between art-of-living and egoism and perfectionism was demonstrated.

With regard to the question of multi-component versus a single component prediction of well-being, all comparisons yield significant enhancements in the prediction of wellbeing by multiple components compared to the best single component.

With respect to incremental validity, it was demonstrated that art-of-living statistically significantly enhanced the prediction of well-being over and above the effect of personality.

Finally, assessing synergistic effects in the prediction of well-being, we found that the amount of unique variance of the components was low compared to the proportion of common variance. This implies that there are synergistic effects between the different components of art-ofliving.

\section{Limitations}

Art-of-living is designed as a multicomponent approach to the prediction of well-being based on the idea that multiple components would be more effective at enhancing wellbeing than a single component. Despite the face validity of this proposition, past empirical results have not uniformly supported the assumed superior effectiveness of multicomponent approaches. Hendriks et al. (2019) found in a meta-analysis that in intervention studies multicomponent approaches did not fare better than single strategies at enhancing well-being. Our results based on cross-sectional analyses clearly indicate the group of art-of-living components is significantly more effective at predicting well-being than any of the components in isolation. It would be interesting to verify whether this finding is transferable to intervention studies. We defined our group of art-of-living components based on philosophical theory. However, there may be alternative ways to construct a group of predictors. Therefore, while our art-of-living approach works well for predicting well-being, we do not discount that there may be other variables that could enhance its prediction. One possible candidate to consider might be humor. Our approach is not unique. Other approaches for multicomponent prediction have been trialed, such as the Orientations to Happiness (OTH; Peterson et al., 2005), which includes pleasure, engagement, and meaning. These orientations are on a broader level and capture only some of the aspects of art-of-living. Psychological capital (PsyCap; Luthans \& Youssef, 2004) is yet another multi-component approach. It is defined as an individual's positive psychological state of development that is characterized by self-efficacy, optimism, hope, and resiliency. PsyCap neither deals with body-related behavior, nor with meaning or social contact. From our point of view, art-of-living is more suitable than OTH or PsyCap for predicting well-being.

In addition to the challenge of selecting the suite of predictors for well-being, there were other limitations. Some of the criteria we used did not have the desired reliability. For instance, some of the PWB components failed to meet the accepted reliability standard. The respective correlations should therefore be considered with caution. However, the PWB is only one of the many criteria investigated in this study.

It should also be noted that our approach is purely correlational, while the idea of art-of-living is to provide a causal pathway to improved well-being. This could be assessed in the future with intervention studies. For our older version of the art-of-living instrument, we developed and evaluated several interventions, and found that enhancing these artof-living strategies improved well-being (Schmitz, 2016).

Also, it could be regarded as a limitation that the relationship between the old and new instruments is not clear. But analyses show (cf. supplementary material 1, Schmitz et al., 2021) that apart from a change of wording the shortened instrument consisting of 11 subconstructs with 35 items shows a high correlation to the long version comprising 17 subconstructs with 131 items. This suggests that the results of former studies with the old instrument must not be completely disregarded.

But independent of this consideration the study at hand showed the psychometric qualities of the new instrument which is far more parsimonious with 35 items. 


\section{Conclusion}

The aim in developing the concept of art-of-living was to systematize the various components which may enhance well-being. It was already known that single strategies can enhance well-being (Sin \& Lyubomirsky, 2009). The goal was to find a multi-component approach that is integrative and holistic. Based on the philosophical art-of-living theory by Schmid (1998, 2004), Schmitz (2016) summarized a group of constructs capable of enhancing happiness. In this study, a new instrument, the AOLI, was validated in both German and English samples. This instrument was found to have good reliability and the factor structure was compatible with the theoretical expectation of 11 components for both samples. Furthermore, art-of-living predicted well-being, showed good convergent and divergent validity (including more objective situational judgment tests), and was distinguishable from personality traits. Further, art-ofliving components show synergistic effects in the prediction of well-being.

The availability of both German and English language versions may be helpful for future research. The art-ofliving approach appears promising in that it may provide people with assistance on their journey to well-being. In personality research (Cattell, 1965), decades of research and hundreds of studies contributed to the development of a widely accepted instrument. Equally, it will take time for well-being predictors to become systematized. The AOLI may be an encouraging step in this direction.

\section{References}

Bolier, L., laverman, M., Westerhof, G. J., Riper, H., Smit, F., \& Bohltmeijer, E. (2013). Positive psychology interventions: A meta-analysis of randomized controlled studies. BMC Public Health, 13(1), Article 119. https://doi.org/10.1186/1471-245813-119

Borkenau, P., \& Ostendorf, F. (2008). NEO-Fünf-Faktoren Inventar (NEO-FFI) nach Costa und McCrae [NEO Five-Factor Inventory (NEO-FFI) according to Costa and McCrae]. Hogrefe.

Bryant, F. B., \& Veroff, J. (2006). Savoring: A new model of positive experience. Routledge.

Cattell, R. B. (1965). The scientific analysis of personality. Penguin Books.

Chen, F. F. (2007). Sensitivity of goodness of fit indexes to lack of measurement invariance. Structural Equation Modeling, 14(3), 464-504. https://doi.org/10.1080/10705510701301834

Deci, E. L., Connell, J. P., \& Ryan, R. M. (1989). Self determination in a work organization. Journal of Applied Psychology, 74(4), 580-590. https://doi.org/10.1037/0021-9010.74.4.580

Diener, E., Emmons, R. A., Larsen, R. J., \& Griffin, S. (1985). The Satisfaction With Life Scale. Journal of Personality Assessment, 49(1), 71-75. https://doi.org/10.1207/s15327752jpa4901_13

Diener, E., Wirtz, D., Tov, W., Kim-Prieto, C., Choi, D.-W., Oishi, S., \& Biswas-Diener, R. (2010). New well-being measures: Short scales to assess flourishing and positive and negative feelings.
Social Indicators Research, 97(2), 143-156. https://doi.org/ 10.1007/s11205-009-9493-y

Esch, T., Jose, G., Gimpel, C., Von Scheidt, C., \& Michalsen, A. (2013). Die Flourishing Scale (FS) von Diener et al. in deutscher Fassung (FS-D) [The Flourishing Scale (FS), German translation of Diener et al.]. Forschende Komplementarmedizin, 20(4), 267-275. https://doi.org/10.1159/000354414

Glaesmer, H., Grande, G., Braehelr, E., \& Roth, M. (2011). The German version of the Satisfaction with Life scale (SWLS). European Journal of Psychological Assessment, 27(2), 127-132. https://doi.org/10.1027/1015-5759/a000058

Greiff, S., \& Scherer, R. (2018). Still comparing apples with oranges? European Journal of Psychological Assessment, 34(3), 141-144. https://doi.org/10.1027/1015-5759/a000487

Harkness, J. A. (2007). Improving the comparability of translations. In R. Jowell, C. Roberts, R. Fitzgerald, \& G. Eva (Eds.), Measuring attitudes cross-nationally: Lessons from the European Social Survey (pp. 79-94). Sage.

Hendriks, T., Schotanus-Dijkstra, M., Hassankhan, A., de Jong, J., \& Bohlmeijer, E. (2020). The efficacy of multi-component positive psychology interventions: A systematic review and meta-analysis of randomized controlled trials. Journal of Happiness Studies, 21(1), 357-390. https://doi.org/10.1007/ s10902-019-00082-1

Hu, L.-T., \& Bentler, P. M. (1999). Cutoff criteria for fit indexes in covariance structure analysis: Conventional criteria versus new alternatives. Structural Equation Modeling, 6(1), 1-55. https:// doi.org/10.1080/10705519909540118

Huta, V., \& Waterman, A. S. (2014). Eudaimonia and its distinction from hedonia: Developing a classification and terminology for understanding conceptual and operational definitions. Journal of Happiness Studies, 15, 1425-1456. https://doi.org/10.1007/ s10902-013-9485-0

Kreitzer, M. J., Gross, C. R., Waleekhachonloet, O.-A., ReillySpong, M., \& Byrd, M. (2009). The Brief Serenity Scale: A psychometric analysis of a measure of spirituality and wellbeing. Journal of Holistic Nursing, 27(1), 7-16. https://doi.org/ 10.1177/0898010108327212

Lazarus, R. S., \& Folkman, S. (1984). Stress, appraisal, and coping. Springer.

Locke, E. A., \& Latham, G. P. (2002). Building a practically useful theory of goal setting and task motivation: A 35-year odyssey. American Psychologist, 57(9), 705-717. https://doi.org/ 10.1037/0003-066X.57.9.705

Luthans, F., \& Youssef, C. M. (2004). Human, social and now positive psychological capital management. Organizational Dynamics, 33(2), 143-160. https://doi.org/10.1016/j.orgdyn. 2004.01.003

Lyubomirsky, S., \& Lepper, H. S. (1999). A measure of subjective happiness: Preliminary reliability and construct validation. Social Indicators Research, 46(2), 137-155. https://doi.org/ 10.1023/A:1006824100041

Lyubomirsky, S., King, L., \& Diener, E. (2005). The benefits of frequent positive affect: Does happiness lead to success? Psychological Bulletin, 131(6), 803-855. https://doi.org/ 10.1037/0033-2909.131.6.803

Martelaa, F., \& Steger, M. F. (2016). The three meanings of meaning in life: Distinguishing coherence, purpose, and significance. The Journal of Positive Psychology, 11(5), 531-545. https://doi.org/10.1080/17439760.2015.1137623

Malthouse, R., \& Roffey-Barentsen, J. (2013). Reflective practise in education and training (2nd ed.). Learning Matters.

Peterson, C., Park, N., \& Seligman, M. E. P. (2005). Orientations to happiness and life satisfaction: The full life versus the empty life. Journal of Happiness Studies, 6(1), 25-41. https://doi.org/ 10.1007/s10902-004-1278-z 
Proyer, R. T., Gander, F., Wellenzohn, S., \& Ruch, W. (2017). The Authentic Happiness Inventory Revisited: Addressing its psychometric properties, validity and role in intervention studies. Journal Well-being Assessment, 1(1-3), 77-96. https://doi.org/10.1007/s41543-018-0006-0

R Core Team. (2015). R: A language and environment for statistical computing. R Foundation for Statistical Computing.

Rosseel, Y. (2012). Lavaan: An R package for structural equation modeling and more. Version 5-12 (BETA). Journal of Statistical Software, 48(2), 1-36. https://doi.org/10.18637/jss.v048.i02

Ryff, C. D. (1989). Happiness is everything, or is it? Explorations on the meaning of psychological well-being. Journal of Personality and Social Psychology, 57(6), 1069-1081. https://doi.org/ 10.1037/0022-3514.57.6.1069

Schmid, W. (1998). Philosophie der Lebenskunst: Eine Grundlegung [Philosophy for the art-of-living. A foundation]. Suhrkamp.

Schmid, W. (2004). Mit sich selbst befreundet sein [To be friends with ourselves]. Suhrkamp.

Schmitz, B. (2016). Art of living. A concept to enhance happiness. Springer.

Schmitz, B., Schumacher, B., Schwarz, M., \& Feldmann, F. (2021). Validation of a German and English version of the Raised Art-ofLiving Inventory - Supplementary materials. http://dx.doi.org/ 10.23668/psycharchives. 4774

Seligman, M. E. (2011). Flourish: A visionary new understanding of happiness and well-being. Heinamann.

Seligman, M. E., Steen, T. A., Park, N., \& Peterson, C. (2005). Positive psychology progress: Empirical validation of interventions. American Psychologist, 60(5), 410-421. https://doi.org/ 10.1037/0003-066X.60.5.410

Sin, N. L., \& Lyubomirsky, S. (2009). Enhancing well-being and alleviating depressive symptoms with positive psychology interventions: a practice-friendly meta-analysis. Journal of Clinical Psychology, 65(5), 467-487. https://doi.org/10.1002/ jclp.20593

Swami, V., Stieger, S., Voracek, M., Dressler, S. G., Eisma, L., \& Furnham, A. (2009). Psychometric evaluation of the Tagalog and German Subjective Happiness Scales and a cross-cultural comparison. Social Indicators Research, 93(2), 393-406. https://doi.org/10.1007/s11205-008-9331-7

Vazire, S., \& Carlson, E. N. (2010). Self-knowledge of personality: Do people know themselves? Social and Personality Psychology Compass, 4(8), 605-620. https://doi.org/10.1111/j.1751-9004. 2010.00280.x

Veenhoven, R. (2003). Arts of living. Journal of Happiness Studies, 4(4), 373-384. https://doi.org/10.1023/B:JOHS.0000005773. 08898.ae

Wilkinson, A., \& Whitehead, L. (2009). Evolution of the concept of self-care and implications for nurses: A literature review. International Journal of Nursing Studies, 46(8), 1143-1147. https://doi.org/10.1016/j.ijnurstu.2008.12.011

\section{History}

Received April 23, 2020

Revision received January 22, 2021

Accepted February 8, 2021

Published online June 1, 2021

EJPA Section / Category Positive Psychology \& Assessment

\section{Acknowledgment}

We thank Esra Ates, Ava Bayat, Nina Helwig, Annika Vetter, Charlotte Hesse, Joelle Ritter, Victoria Präger, Jacqueline Büchner, Andriana Lespukh, Michelle Cherrez Chica, Maria Rebecca Thissen, Lina Geißler, Leandra Williams, Christian Bausch, Sebastian Felk, Philipp Hengst, and Marco Zlojutro for their support in data collection and analyses.

\section{Open Science}

Open Data: The information needed to reproduce all of the reported results are not openly accessible.

Open Materials: The information needed to reproduce all of the reported methodology is not openly accessible. The supplementary materials for this paper are accessible at http://dx.doi.org/ 10.23668/psycharchives.4774.

Preregistration of Studies and Analysis Plans: This study was not preregistered.

We report if necessary, all data exclusions (if any), all data inclusion/exclusion criteria, whether inclusion/exclusion criteria were established prior to data analysis, all measures in the study, and all analyses including all tested models. If we use inferential tests, we report exact $p$ values and effect sizes.

\section{Funding}

With respect to Open Access publishing we acknowledge support by the Deutsche Forschungsgemeinschaft (DFG German Research Foundation) and enabled by the Technical University of Darmstadt.

\section{ORCID}

Bernhard Schmitz

(iD) https://orcid.org/0000-0002-6034-6674

\section{Bernhard Schmitz}

Department of Psychology

Technical University of Darmstadt

Alexanderstr. 10

64283 Darmstadt

Germany

schmitz@psychologie.tu-darmstadt.de 